\title{
Estudo comparativo entre os parâmetros reológicos de tintas acrílicas arquitetônicas
}

\author{
Comparative study between the rheological parameters \\ of architectural acrylic paints
}

\author{
Amanda Moreira Lima Machado \\ Camila Carvalho Noberto \\ Francisco Estevão Damasceno Filho \\ Wyoskynaria Mihaly Maia da Silva \\ Lucas Feitosa de Albuquerque Lima Babadopulos \\ Marcelo Silva Medeiros Júnior
}

\section{Resumo}

${ }^{1}$ Amanda Moreira Lima Machado 'Universidade Federal do Ceará Fortaleza - CE - Brasil

${ }^{2}$ Camila Carvalho Noberto ¿Universidade Federal do Ceará Fortaleza - CE - Brasil

${ }^{3}$ Francisco Estevão Damasceno

Filho

${ }^{3}$ Universidade Federal do Ceara Fortaleza - CE - Brasil

${ }^{4}$ Wyoskynaria Mihaly Maia da Silva

${ }^{4}$ Universidade Federal do Ceara Fortaleza - CE - Brasil

${ }^{5}$ Lucas Feitosa de Albuquerque Lima Babadopulos ${ }^{5}$ Universidade Federal do Ceará Fortaleza - CE - Brasil

${ }^{6}$ Marcelo Silva Medeiros Júnior ${ }^{6}$ Universidade Federal do Ceara Fortaleza - CE - Brasil

Recebido em 14/03/21 Aceito em 18/08/21

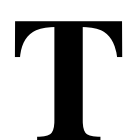

intas acrílicas são amplamente utilizadas em construção para fornecer proteção e tonalidade. Para garantir seu desempenho nas diferentes condições de uso (cisalhamento) a que são submetidas, pode-se estudar sua reologia. Um estudo foi realizado com seis tintas comerciais, classificadas como Econômica, Standard e Premium, de dois fabricantes (A e B), nas diluições, em volume, de $0 \%, 10 \%$ e $20 \%$. Foram realizados ensaios de fluxo, de varredura de frequência e de tixotropia. No ensaio de fluxo, houve bastante variabilidade nos valores de viscosidade aparente até a taxa de $1 \mathrm{~s}^{-1}$. Por meio da caracterização de tixotropia, observou-se que as tintas do fabricante B recuperam a viscosidade inicial mais rapidamente, após serem submetidas a uma alta taxa de cisalhamento. Demonstrou-se uma associação entre o rendimento das tintas, que é um indicador prático utilizado na indústria, e a viscosidade aparente a $3.000 \mathrm{~s}^{-1}$ $\left(\mathrm{R}^{2}=86 \%\right)$. A varredura de frequência mostrou que as tintas da classe Premium possuem menor estabilidade, devido ao seu elevado módulo de perda (G”). Conclui-se que a reologia é uma ferramenta útil e necessária para melhorar a compreensão do comportamento das tintas e adaptá-las para uso e aplicação.

Palavras-chave: Tinta acrílica. Reologia. Fluxo. Tixotropia. Varredura de frequência.

\section{Abstract}

Acrylic paints are widely used in construction for providing protection and color. In order to ensure their performance at the different conditions of service (shear) to which they are submitted to, their rheology can be studied. A study was carried out with six commercial paints, classified as Economy, Standard and Premium, from two manufacturers (A and B), under the dilutions, by volume, of $0 \%, 10 \%$ and $20 \%$. Flow tests, frequency sweep tests and thixotropy tests were performed. For the flow curves, there was relevant variability on apparent viscosity for values up to the shear rate of $1 \mathrm{~s}^{-1}$. Standard Paints were less likely to sediment and sag, due to their high apparent viscosity at low shear rates. As per the thixotropy characterization, it was observed that the paints from manufacturer $B$ were quicker to recover the initial viscosity after subjected to a high shear rate. An association between the yield of the paints, which is a practical indicator used in industry, and the apparent viscosity at $3000 \mathrm{~s}^{-1}\left(R^{2}=86 \%\right)$ was demonstrated. The frequency sweep showed that the Premium paints were less stable, due to their high loss modulus (G"). It is concluded that rheology is a useful and necessary tool to enhance understanding of paint behavior and adapt them to use and application.

Keywords: Acrylic paint. Rheology. Flow. Thixotropy. Frequency sweep.

MACHADO, A. M. L.; NOBERTO, C. C.; DAMASCENO FILHO, F. E.; SILVA, W. M. M. da; BABADOPULOS, L. F. de A. L.; MEDEIROS JÚNIOR, M. S. Estudo comparativo entre os parâmetros reológicos de tintas acrílicas arquitetônicas.

Ambiente Construído, Porto Alegre, v. 22, n. 1, p. 223-240, jan./mar. 2022.

ISSN 1678-8621 Associação Nacional de Tecnologia do Ambiente Construído.

http: //dx.doi.org/10.1590/s1678-86212022000100589 


\section{Introdução}

As tintas são misturas que formam um filme quando aplicadas sobre uma superfície e têm como objetivo dar proteção e cor ao substrato, propiciando o seu embelezamento. Elas geralmente se apresentam no estado líquido, sendo compostas por resinas, pigmentos e solventes, cargas minerais e outros aditivos que possuem diversas finalidades (MELLO; SUAREZ, 2012).

Para atingir todos os requisitos de desempenho das tintas é necessário que, na etapa de formulação, seu comportamento durante o uso e aplicação seja levado em consideração. Isso é fundamental, pois a tinta está sujeita a diversas condições de cisalhamento. Durante a etapa de armazenamento e transporte há uma condição de baixo cisalhamento, já durante a aplicação essa taxa é maior e diferente para cada método utilizado (NASCIMENTO; PINTO; SIRQUEIRA, 2015).

O Brasil é um dos cinco maiores mercados mundiais para tintas, possuindo inovações técnicas e tecnológicas que podem ser comparadas aos centros mundiais de produção avançados. Nesse mercado, destacam-se as tintas imobiliárias, cujo volume total produzido, em 2020, foi de 1.354 bilhões de litros, correspondendo a $83,4 \%$ da produção total de tintas no país (ABRAFATI, 2019).

Além disso, por meio da literatura, percebeu-se que grande parte dos atuais estudos nessa área é relacionada a análises dos componentes químicos, como em Sirqueira et al. (2016), que estudaram a influência do teor do polímero polianilina no comportamento reológico de tintas acrílicas. Já Karakaş e Çelik (2018) estudaram mecanismos de estabilização dos pigmentos de tintas. Além desses, Amorim et al. (2021) estudaram tintas epoxídicas para a indústria naval com carga condutora e nanopartículas, com foco na resistência à corrosão. Cardoso et al. (2016) avaliaram tintas produzidas com pigmentos de solos provenientes de três municípios, com base na norma brasileira de desempenho de tintas para edificações não industriais, e verificaram que nenhuma dessas tintas atendia a todos os critérios estabelecidos, simultaneamente.

Diante disso, percebe-se a importância desse setor e dos estudos voltados às tintas arquitetônicas, com destaque para as tintas acrílicas, que têm uso mais abrangente por apresentarem propriedades como fácil manuseio, solubilidade em água e rápida secagem (FARDI et al., 2018). De acordo com a NBR 11702 (ABNT, 2019a), as tintas indicadas para uso em alvenarias em geral são chamadas de tintas látex, as quais são à base de dispersão polimérica em meio aquoso, podendo ser constituída de polímeros acrílicos, vinílicos, entre outros (ABRAFATI, 2019). O Quadro 1 apresenta a classificação dos tipos das tintas para alvenarias de acordo com a NBR 15079-1 (ABNT, 2019c).

Estudar a reologia desse fluido é fundamental para que se consiga prever e caracterizar seu desempenho, tanto com relação à facilidade e à adequabilidade da aplicação, quanto à manutenção de suas propriedades ao longo do tempo, de modo a adequá-lo ao uso. Por meio dela é possível investigar a resistência ao fluxo e à deformação, que influenciam, diretamente, no comportamento das tintas. Portanto, conhecer os parâmetros reológicos das tintas se torna crucial quando se quer atender a um padrão de qualidade e, além disso, gerar satisfação aos clientes (ELEY, 2019). Dessa forma, é necessário que as tintas apresentem características específicas, como pseudoplasticidade, tixotropia e viscoelasticidade para que seu comportamento (nivelamento, dispersão dos pigmentos, resistência ao escorrimento e à sedimentação durante o armazenamento, entre outros) não seja afetado (ELEY, 2019; VERKHOLANTSEV, 1999).

\section{Quadro 1 - Classificação das tintas para alvenarias}

\begin{tabular}{|l|l|}
\hline \multicolumn{1}{|c|}{ Tipo } & \multicolumn{1}{c|}{ Descrição } \\
\hline Tintas econômicas & $\begin{array}{l}\text { Correspondem ao menor nível de desempenho, independentemente do tipo de } \\
\text { acabamento proporcionado, indicada exclusivamente para ambientes interiores. }\end{array}$ \\
\hline Tintas standard & $\begin{array}{l}\text { Independentemente do tipo de acabamento proporcionado é indicada para ambientes } \\
\text { interiores e/ou exteriores, com desempenho inferior ao das tintas premium. }\end{array}$ \\
\hline Tintas premium & $\begin{array}{l}\text { Independentemente do tipo de acabamento proporcionado é indicada para ambientes } \\
\text { interiores e/ou exteriores, com desempenho superior ao das tintas standard. }\end{array}$ \\
\hline $\begin{array}{l}\text { Tintas super } \\
\text { premium }\end{array}$ & $\begin{array}{l}\text { Independentemente do tipo de acabamento proporcionado é indicada para ambientes } \\
\text { interiores e/ou exteriores, com desempenho superior ao das tintas premium. }\end{array}$ \\
\hline
\end{tabular}

Fonte: NBR 15079-1 (ABNT, 2019c). 
Este artigo tem o objetivo de realizar um estudo comparativo do comportamento reológico de tintas acrílicas. Para isso, utilizaram-se seis tintas comerciais das classes econômica, standard e premium, sob diluições de $0 \%, 10 \%$ e $20 \%$, com a finalidade de observar o comportamento reológico das amostras e relacioná-lo a algumas das características técnicas das tintas.

\section{Reologia de tintas}

\section{Principais propriedades e manifestações de comportamentos reológicos}

Os fluidos podem ser classificados quanto ao seu comportamento reológico em dois grandes grupos: newtonianos e não newtonianos. Os newtonianos são aqueles cuja curva de fluxo (tensão de cisalhamento versus taxa de cisalhamento) é linear, sendo sua viscosidade independente da tensão e da taxa de cisalhamento e dependente apenas do material e de sua temperatura e pressão. Já os não newtonianos são aqueles cuja curva de fluxo não é linear, apresentando uma viscosidade aparente que depende das condições do fluxo (CHHABRA; RICHARDSON, 2008). A Figura 1a mostra o comportamento dos fluidos newtonianos e não newtonianos independentes do tempo (Herschel-Bulkley, fluido de Bingham, pseudoplástico, newtoniano e dilatante). Já a Figura $1 \mathrm{~b}$ mostra o comportamento dos fluidos não newtonianos dependentes do tempo (fluidos tixotrópicos e reopéticos).

De modo geral, as tintas são compostas por uma parcela viscosa e por outra elástica, sendo consideradas, assim, um material viscoelástico, altamente dependente do tempo (LEE, 2020; MOOLMAN, 2008). A parcela elástica resiste instantaneamente à deformação, recuperando-se quando a força externa é retirada. Já a parcela viscosa é dependente do tempo devido ao fluxo induzido pela força externa aplicada, o qual é oposto à viscosidade do material (CHAKRABORTY; RATNA, 2020).

Segundo Moolman (2008), a viscoelasticidade dos materiais pode ser investigada utilizando reômetro rotacional e oscilatório. Os testes oscilatórios são usados para caracterizar todos os tipos de comportamento viscoelástico e empregam varreduras de frequência (teste de diferentes frequências de oscilação a uma dada temperatura). $\mathrm{O}$ teste de varredura de frequência constitui umas das possibilidades de obter informações da amostra sem destruir sua estrutura (limitando a amplitude de deformação aplicada). Esse método está relacionado ao tempo, fornecendo informações importantes do comportamento do material durante um período de curto ou longo prazo. Elas podem ser obtidas utilizando ensaios oscilatórios, de vaivém da taxa de cisalhamento, com medida de uma propriedade conhecida como módulo complexo, a qual apresenta uma parte real (módulo de armazenamento - G') e outra complexa (módulo de perda - G'), em diferentes frequências de oscilação.

As tintas apresentam estrutura e fluxo complexos, não podendo ser descritas apenas com o valor da viscosidade aparente a uma dada taxa de cisalhamento. O comportamento delas deve ser pseudoplástico, pois espera-se que a viscosidade aparente das tintas diminua com o aumento da taxa de cisalhamento aplicada (MCKEEN, 2016).

\section{Figura 1 - Comportamento dos fluidos (a) independentes do tempo e (b) dependentes do tempo}

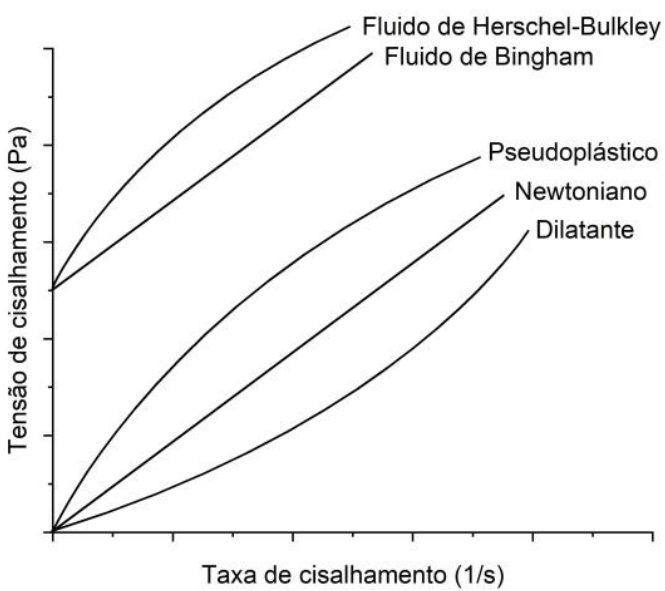

(a)

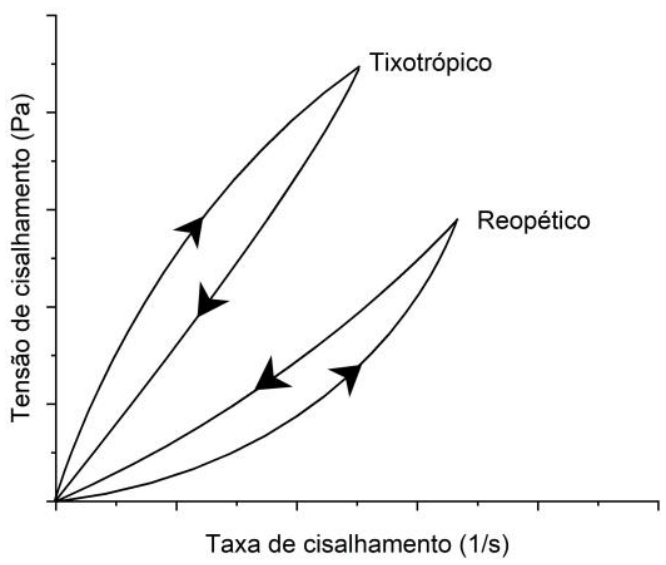

(b)

Fonte: adaptado de Chhabra e Richardson (2008). 
Há ainda relevante caráter tixotrópico a considerar (BHAVSAR; SHREEPATHI, 2016). Tixotropia é o fenômeno em fluidos de modificação reversível de viscosidade aparente quando da manutenção de diferentes taxas de cisalhamento no material ao longo do tempo (MEWIS; WAGNER, 2009). Pode ser subdividida em dois subfenômenos. O primeiro é o breakdown (desestruturação) da microestrutura, que reduz a viscosidade aparente na macroescala a partir de fenômenos na microescala. Isso ocorre após a aplicação ao longo do tempo de taxas de cisalhamento altas comparadas ao histórico anterior de carregamento. O segundo é o build-up (reestruturação) da microestrutura, que, inversamente, aumenta a viscosidade aparente na macroescala a partir de modificações na microestrutura. Isso ocorre após a aplicação ao longo do tempo de taxas de cisalhamento baixas comparadas ao histórico anterior de carregamento. Ambos os fenômenos ocorrem simultaneamente e uma viscosidade de equilíbrio tende a ser obtida após certo tempo de aplicação de uma taxa de cisalhamento fixa. A viscosidade aparente de equilíbrio depende da taxa de cisalhamento aplicada.

\section{Relação entre as propriedades e o desempenho das tintas}

Diversos comportamentos observáveis em campo estão associados à reologia das tintas, tais como sedimentação, escorrimento, nivelamento, resistência a respingos, formação de filme, etc. (BHAVSAR; SHREEPATHI, 2016; DEKA; DEY, 2013; ELEY, 2019; MCKEEN, 2016; MOOLMAN, 2003). Por exemplo, baixas viscosidades aparentes em taxas de cisalhamento intermediárias e muito baixas viscosidades aparentes em altas taxas de cisalhamento são necessárias para facilitar bombeamento e aplicação com spray, respectivamente. Suficiente viscosidade aparente em taxas de cisalhamento muito baixas é necessária para evitar escorrimento. Nesse sentido, a comparação entre as tintas em função do comportamento esperado na aplicação pode ser feita com base na comparação entre os próprios valores de viscosidade aparente nas taxas de cisalhamento pertinentes.

Segundo Eley (2019), a reologia está bem relacionada com o desempenho das tintas arquitetônicas, e é importante que alguns requisitos de aplicação sejam levados em consideração, como: fluxo e nivelamento aceitáveis para cada aplicação, ausência de marcas de escorrimento ou gotejamento, facilidade de aplicação por pincel, resistência a respingos quando se usa rolos, tempo de abertura suficiente para retirar ou espalhar novamente e resistência a fluxos induzidos por tensão superficial indesejados.

As tintas estão sujeitas a variadas formas de distribuição de tensões ao serem aplicadas ao substrato, seja com auxílio do pincel ou rolo, resultando em altas taxas de cisalhamento a depender da espessura da camada e da velocidade de aplicação. Contudo, durante a adesão à superfície, pequenas forças influenciam, e as taxas de cisalhamento são menores que $10^{-3} \mathrm{~s}^{-1}$ (MOOLMAN, 2003).

De acordo com McKeen (2016), deve-se considerar que a viscosidade aparente do material vai depender tanto da taxa e da tensão de cisalhamento, que podem ser aplicadas durante as medições e os processos de uso, quanto da temperatura e do modo de aplicação do revestimento. Diante disso, a Figura 2 associa uma variação de taxas de cisalhamento a vários processos importantes para manter o desempenho das tintas, representando essas taxas em uma curva de fluxo (viscosidade aparente em função da taxa de cisalhamento aplicada).

Segundo Deka e Dey (2013), o perfil de viscosidade a uma taxa muito baixa de cisalhamento fornece informações relacionadas às propriedades de sedimentação, escorrimento, fluxo e nivelamento. Já o perfil médio está relacionado à consistência da mistura e à aparência da tinta na embalagem. Enquanto isso, o perfil de viscosidade à alta taxa de cisalhamento permite uma melhor correlação com as propriedades de aplicação, como aplicação por pincel, resistência a respingos, formação de filme, entre outros.

A caracterização da viscosidade aparente a uma dada taxa de cisalhamento não é suficiente para a compreensão do comportamento da tinta. Fenômenos como o escorrimento, por exemplo, também são relevantemente influenciados pela tixotropia (BHAVSAR; SHREEPATHI, 2016). A viscosidade aparente das tintas deve se manter relativamente baixa por tempo suficientemente longo após a aplicação, independentemente do método adotado, recuperando sua viscosidade mais elevada após certo tempo. Esse é um caráter essencialmente tixotrópico, e evita imperfeições no acabamento (ARMELIN et al., 2006; SEELER et al., 2017). 
Figura 2 - Perfil reológico (representado em uma curva de fluxo) de tintas em taxas de cisalhamento associadas às diferentes fases de sua aplicação

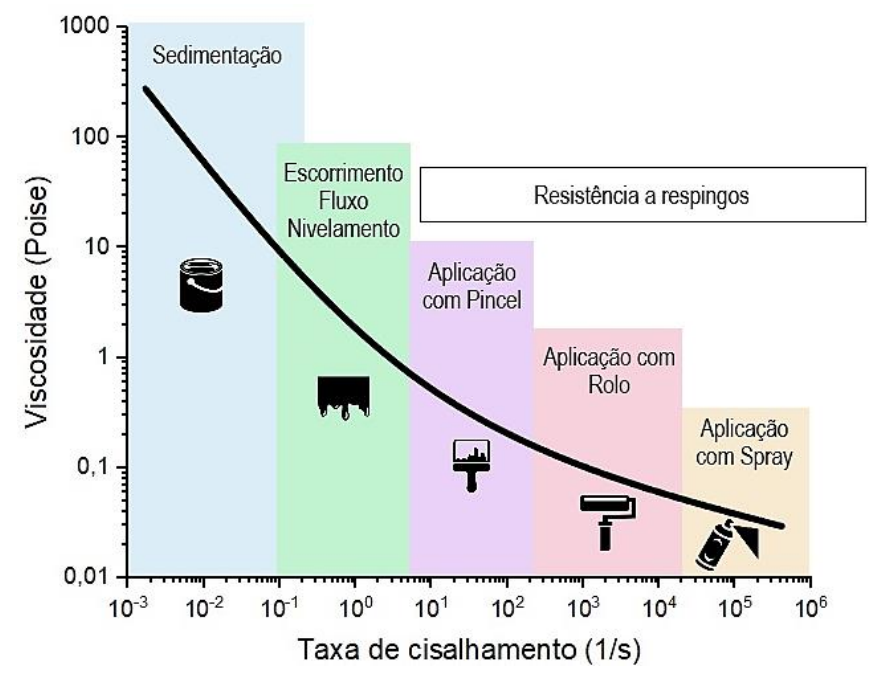

Fonte: adaptado de Deka e Dey (2013).

Nivelamento e resistência ao escorrimento também são fortemente influenciados por comportamento tixotrópico (BHAVSAR; SHREEPATHI, 2016). O nivelamento é relacionado à própria viscosidade aparente a uma dada taxa de cisalhamento e ainda à sua variação temporal, devendo ter valor suficientemente alto. $\mathrm{O}$ escorrimento é associado a baixas viscosidades aparentes e a tempos elevados para a recuperação por tixotropia (build-up). Fica claro, portanto, que quanto mais rápido o material recuperar a viscosidade, após aplicação de uma alta taxa de cisalhamento, menor será a probabilidade de ocorrer o escorrimento da tinta, devendo-se, porém, permitir o tempo necessário para que ocorra o nivelamento, para obtenção de um filme uniforme. De acordo com Bhavsar e Shreepathi (2016), 100s após a retirada da alta taxa de cisalhamento é um tempo razoável para que a tinta flua e nivele, intervalos superiores contam com alguns riscos indesejáveis, como evaporação da água, perda de solvente e escorrimento. Espera-se, então, que as tintas sejam tixotrópicas, ou seja, que a sua viscosidade aparente inicial se recupere ao longo do tempo para evitar o escorrimento da camada recém-aplicada, uma vez que, durante a aplicação, ao ser submetida a maiores taxas de cisalhamento, sua viscosidade aparente é reduzida.

Quanto ao comportamento viscoelástico das tintas, mencionado na seção anterior, observa-se que, de acordo com Moolman (2003), valores de módulo de perda (G”) maiores que do módulo de armazenamento (G') sugerem provável sedimentação nas tintas. O referido autor usou ensaios de varredura de frequência para avaliar o risco desse fenômeno.

\section{Materiais e método}

\section{Materiais}

As tintas escolhidas para serem utilizadas neste estudo foram seis tintas acrílicas à base de água, das classes econômica - fosca, standard - fosca e premium - semibrilho, indicadas para revestimento de alvenarias, produzidas por duas empresas, A e B, na cidade de Fortaleza, Ceará, Brasil. As tintas do fabricante A foram chamadas de "tinta A", e as do fabricante B de "tinta B". De acordo com os fabricantes, todas as amostras são classificadas e estão em conformidade com as normas da ABNT: NBR 11702 (ABNT, 2019a), NBR 15079-1 (ABNT, 2019c) e NBR 15079-2 (ABNT, 2019d). Na Tabela 1, a descrição das tintas, fornecida pelos fabricantes, é apresentada. Na Tabela 2, apresenta-se a caracterização das tintas com relação à densidade, à viscosidade de fornecimento, à porcentagem de voláteis e ao teor de sólidos, conforme descrição dos fabricantes. Algumas informações das tintas do fabricante A não puderam ser divulgadas e discutidas neste trabalho. Cada tinta foi ensaiada quanto à reologia em diluições de $0 \%, 10 \%$ e $20 \%$, de acordo com as recomendações dos fabricantes. 
Tabela 1 - Descrição das amostras utilizadas

\begin{tabular}{l|l|l|l|c}
\hline \multicolumn{1}{c|}{ Tinta } & Acabamento & \multicolumn{1}{c|}{ Aplicação } & \multicolumn{1}{c}{ Secagem } & Rendimento médio \\
\hline $\begin{array}{l}\text { Tinta A - } \\
\text { econômica }\end{array}$ & Fosco & Interiores & $\begin{array}{l}\text { Ao toque: } 30 \mathrm{~min} \\
\text { Entre demãos: } 4 \mathrm{~h} \\
\text { Final: 4h }\end{array}$ & $9,71 \mathrm{~m} / 1$ \\
\hline $\begin{array}{l}\text { Tinta A - } \\
\text { standard }\end{array}$ & Fosco & Interiores e exteriores & $\begin{array}{l}\text { Ao toque: } 30 \mathrm{~min} \\
\text { Entre demãos: } 4 \mathrm{~h} \\
\text { Final: 4h }\end{array}$ & $11,81 \mathrm{~m} / 1$ \\
\hline $\begin{array}{l}\text { Tinta A - } \\
\text { premium }\end{array}$ & Semibrilho & Interiores e exteriores & $\begin{array}{l}\text { Ao toque: } 30 \mathrm{~min} \\
\text { Entre demãos: } 4 \mathrm{~h} \\
\text { Final: 4h }\end{array}$ & $10,42 \mathrm{~m} / 1$ \\
\hline $\begin{array}{l}\text { Tinta B - } \\
\text { econômica }\end{array}$ & Fosco & Interiores & $\begin{array}{l}\text { Ao toque: } 30 \mathrm{~min} \\
\text { Entre demãos: } 4 \mathrm{~h} \\
\text { Final: } 18 \text { a 24h }\end{array}$ & $16,67 \mathrm{~m} / 1$ \\
\hline $\begin{array}{l}\text { Tinta B - } \\
\text { standard }\end{array}$ & Fosco & Interiores e exteriores & $\begin{array}{l}\text { Ao toque: } 30 \mathrm{~min} \\
\text { Entre demãos: } 4 \mathrm{~h} \\
\text { Final: } 24 \mathrm{~h}\end{array}$ & $22,22 \mathrm{~m} / 1$ \\
\hline $\begin{array}{l}\text { Tinta B - } \\
\text { premium }\end{array}$ & Semibrilho & Interiores e exteriores & $\begin{array}{l}\text { Ao toque: } 30 \mathrm{~min} \\
\text { Entre demãos: } 4 \mathrm{~h} \\
\text { Final: } 18 \text { a 24h }\end{array}$ & $35,00 \mathrm{~m} / 1$ \\
\hline
\end{tabular}

Tabela 2 - Caracterização das amostras utilizadas

\begin{tabular}{l|l|l|l|l}
\hline \multicolumn{1}{c|}{ Tinta } & \multicolumn{1}{|c|}{$\begin{array}{c}\text { Densidade } \\
\left(\mathbf{g} / \mathbf{c m}^{\mathbf{3}}\right)\end{array}$} & $\begin{array}{c}\text { \% } \\
\text { Voláteis }\end{array}$ & $\begin{array}{c}\text { Viscosidade } \\
\text { Krebs Stomer }\end{array}$ & $\begin{array}{c}\text { Teor de sólidos + \% } \\
\text { não voláteis (NV) }\end{array}$ \\
\hline $\begin{array}{l}\text { Tinta A - } \\
\text { econômica }\end{array}$ & $1,400+/-0,05$ & $\mathrm{NDF}^{*}$ & $90 \mathrm{KU}$ & $\mathrm{NDF}$ \\
\hline $\begin{array}{l}\text { Tinta A }- \\
\text { standard }\end{array}$ & $1,320+/-0,02$ & $\mathrm{NDF}$ & $90 \mathrm{KU}$ & $\mathrm{NDF}$ \\
\hline $\begin{array}{l}\text { Tinta A }- \\
\text { premium }\end{array}$ & $1,200+/-0,02$ & $\mathrm{NDF}$ & $90 \mathrm{KU}$ & $\mathrm{NDF}$ \\
\hline $\begin{array}{l}\text { Tinta B }- \\
\text { econômica }\end{array}$ & $1,210 \pm 0,015$ & $63+/-3$ & $90-100 \mathrm{KU}$ & $37+/-3 \%$ de NV \\
\hline $\begin{array}{l}\text { Tinta B }- \\
\text { standard }\end{array}$ & $1,260 \pm 0,030$ & $48+/-3$ & $90-100 \mathrm{KU}$ & $52+/-3 \%$ de NV \\
\hline $\begin{array}{l}\text { Tinta B }- \\
\text { premium }\end{array}$ & $1,270 \pm 0,030$ & $68+/-3$ & $90-100 \mathrm{KU}$ & $32+/-3 \%$ de NV \\
\hline
\end{tabular}

Nota: "NDF: informação não teve permissão pelo fabricante para discussão no artigo.

\section{Caracterização reológica}

A caracterização reológica foi realizada no reômetro AR - 2000 da TA Instruments. Para a análise foram realizados os seguintes ensaios: ensaio de fluxo, varredura de frequência e tixotropia. Cada ensaio foi realizado para cada tipo de tinta nas diluições de $0 \%, 10 \%$ e $20 \%$, totalizando 18 amostras por ensaio. O processo de diluição das tintas consistiu em adicionar a quantidade de água correspondente aos teores de $10 \%$ e $20 \%$ em volume de tinta, sendo, em seguida, misturada em um agitador mecânico na velocidade de $200 \mathrm{rpm}$ (Figura 3) durante dois minutos, de forma a garantir a homogeneidade e a não formação de bolhas à tinta diluída, para que isso não influenciasse nos resultados.

Devido ao tempo de duração de alguns procedimentos e de maneira a evitar efeitos de secagem nos resultados medidos, para cada ensaio uma nova amostra foi utilizada. Conforme observado na literatura (BHAVSAR; SHREEPATHI, 2016; DEKA; DEY, 2013; ZHANG et al., 2015), optou-se por não realizar repetições dos ensaios.

228 Machado, A. M. L.; Noberto, C. C.; Damasceno Filho, F. E.; Silva, W. M. M. da; Babadopulos, L. F. de A. L.; Medeiros Júnior, M. S. 


\section{Figura 3 - Etapa de diluição das amostras}

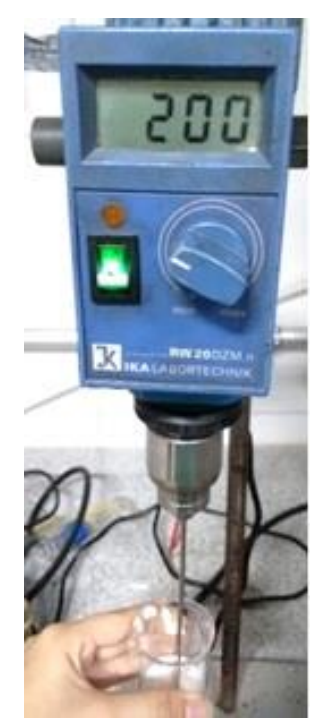

Para todos os procedimentos de ensaios reológicos neste trabalho, utilizou-se a geometria cone-placa, escolhida devido às suas condições de cisalhamento homogêneas, em que a taxa é aproximadamente uniforme em todo o espaço cônico, que corresponde a cerca de 0,3 $\mathrm{ml}$. Além disso, necessita-se de uma pequena amostra, a limpeza é fácil e segura e há a eliminação de bolhas de ar antes do início dos ensaios (MEZGER, 2012). A geometria utilizada possuía $40 \mathrm{~mm}$ de diâmetro e $1^{\circ}$ de ângulo, com gap de $27 \mu \mathrm{m}$. Todos os ensaios foram realizados à temperatura de $25^{\circ} \mathrm{C}$. O controle de temperatura foi feito com o uso de uma placa Peltier, dispositivo capaz de levar a amostra à temperatura desejada em alguns minutos. Os ensaios foram iniciados apenas após as amostras atingirem os $25^{\circ} \mathrm{C}$.

Vale destacar que se utilizou a abordagem de controle de deformação na realização dos procedimentos, em que o material é colocado entre duas superfícies e um deslocamento angular (que se traduz em uma deformação de cisalhamento) é aplicado a uma delas. O torque (e consequente tensão de cisalhamento) aplicado para rotação dessa superfície é medido.

Os ensaios realizados e seus parâmetros são descritos abaixo:

(a) ensaio de fluxo: para remover qualquer histórico de tensões relacionado às condições de armazenamento e de carregamento, inicialmente a amostra foi submetida a um pré-cisalhamento com uma velocidade angular correspondente a $0,1 \mathrm{~Hz}$ ( 1 ciclo a cada $10 \mathrm{~s})$ por $5 \mathrm{~min}$, o que corresponde a $35,63 \mathrm{~s}^{-1}$ de taxa de cisalhamento com a geometria utilizada. Em seguida, para gerar as curvas de fluxo, a viscosidade aparente foi obtida com a variação da taxa de cisalhamento, de $10^{-4}$ a $5.500 \mathrm{~s}^{-1}$. Esse tipo de ensaio foi utilizado, pois, com ele, é possível prever, por exemplo, capacidades de espalhamento e condições de aplicabilidade (DEKA; DEY, 2013). A Figura 4 representa um gráfico esquemático do ensaio, além de associá-lo a uma representação típica de medidas obtidas;

(b) ensaio de tixotropia: o ensaio utilizado foi o Three Interval Thixotropy Test (3ITT), no qual o material em análise é submetido a três blocos de carregamento variando a taxa de cisalhamento de cada bloco. Primeiramente, as tintas foram submetidas a uma taxa de cisalhamento de $0,100 \mathrm{~s}^{-1}$ por $120 \mathrm{~s}$. Em seguida, essa taxa é elevada para $3.000 \mathrm{~s}^{-1}$, a qual foi aplicada por 120s. Finalmente, a taxa é reduzida para $0,100 \mathrm{~s}^{-1}$, sendo aplicada por 300s. Nessa metodologia, a elevação brusca da taxa de cisalhamento é capaz de provocar a desestruturação (breakdown) e, quando essa taxa volta à inicial, pode-se observar a recuperação (build-up) da viscosidade da amostra no decorrer do tempo (BHAVSAR; SHREEPATHI, 2016). O intervalo de baixa taxa de cisalhamento, seguido por um de taxa elevada, retornando para uma baixa taxa são correspondentes às ações de cobrir o rolo ou pincel com a tinta, aplicá-la e o nivelamento da tinta na superfície, respectivamente. Avalia-se a recuperação relativa de viscosidade aparente ao longo do último bloco de carregamento. Isso é feito comparando-se a viscosidade aparente em um determinado instante $\left(\eta_{\mathrm{t}}\right)$ com a viscosidade aparente média medida no primeiro bloco de carregamento a $0,100 \mathrm{~s}^{-1}$ de taxa de cisalhamento. A Figura 5 representa o carregamento aplicado no ensaio, resultados típicos obtidos e a análise correspondente; e 
(c) ensaio varredura de frequência: este ensaio foi realizado aplicando uma amplitude de deformação de cisalhamento controlada de $1 \%$ e uma variação de frequência de 0,10 a $500 \mathrm{rad} / \mathrm{s}$, semelhante ao procedimento adotado por Zhang et al. (2015). Esse ensaio permite compreender melhor o comportamento viscoelástico do material, através dos módulos de armazenamento, G', e de perda, G” à temperatura de 25 ${ }^{\circ} \mathrm{C}$. A Figura 6 representa o carregamento executado em ensaios oscilatórios nas tintas, assim como as medidas obtidas.

Figura 4 - Gráfico esquemático do ensaio de fluxo

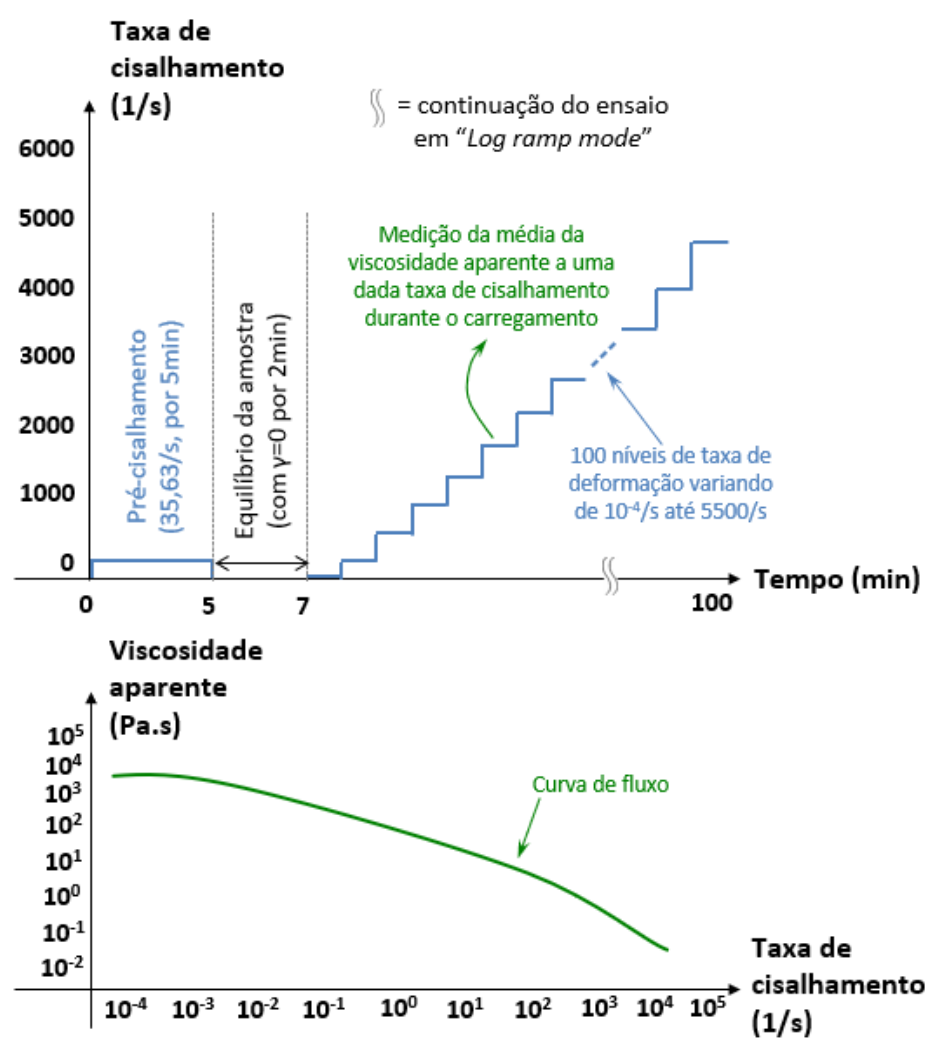

Figura 5 - Gráfico esquemático do ensaio de tixotropia

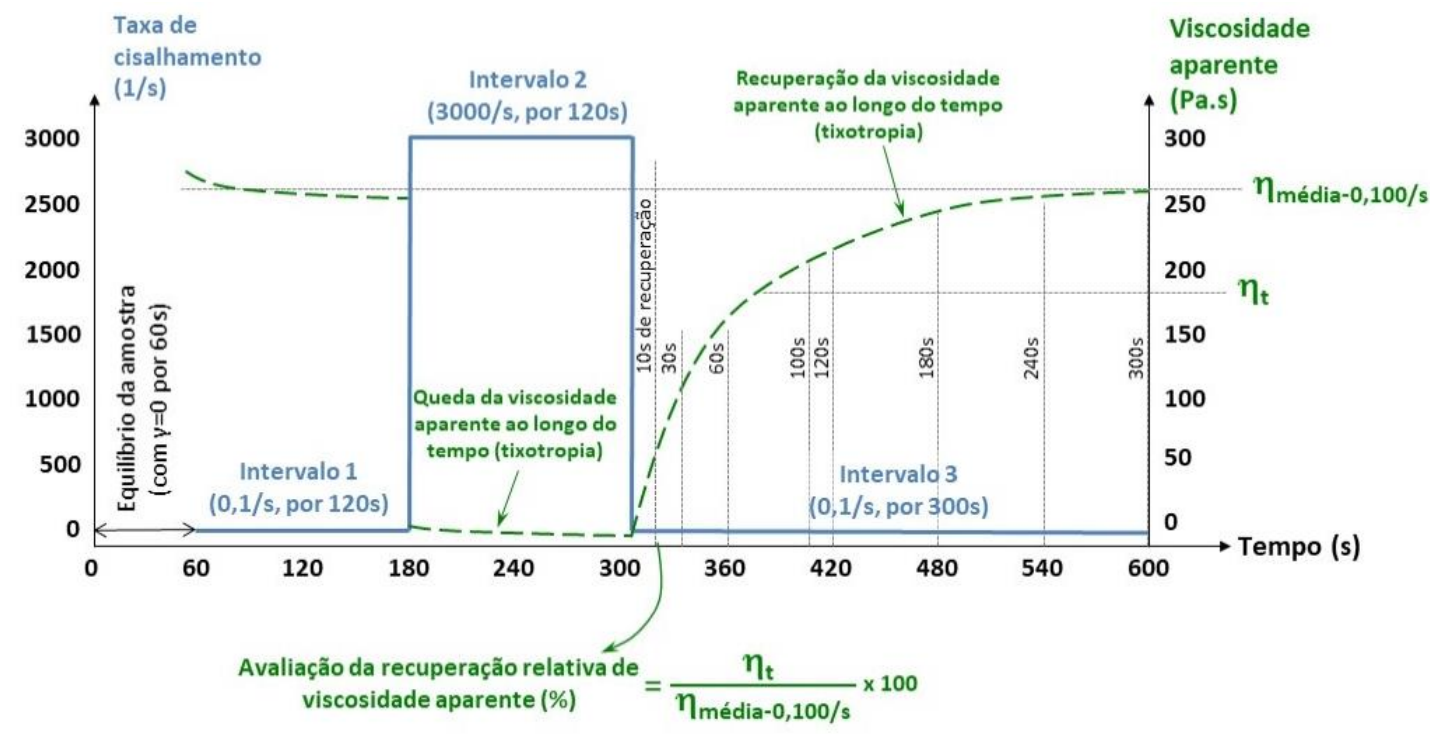

230 Machado, A. M. L.; Noberto, C. C.; Damasceno Filho, F. E.; Silva, W. M. M. da; Babadopulos, L. F. de A. L.; Medeiros Júnior, M. S. 
Figura 6 - Gráfico esquemático do ensaio de varredura de frequência

Repouso (com $\gamma=0$ ) por $2 \mathrm{~min}$ após Equilíbrio térmico $\left(25^{\circ} \mathrm{C}\right)$

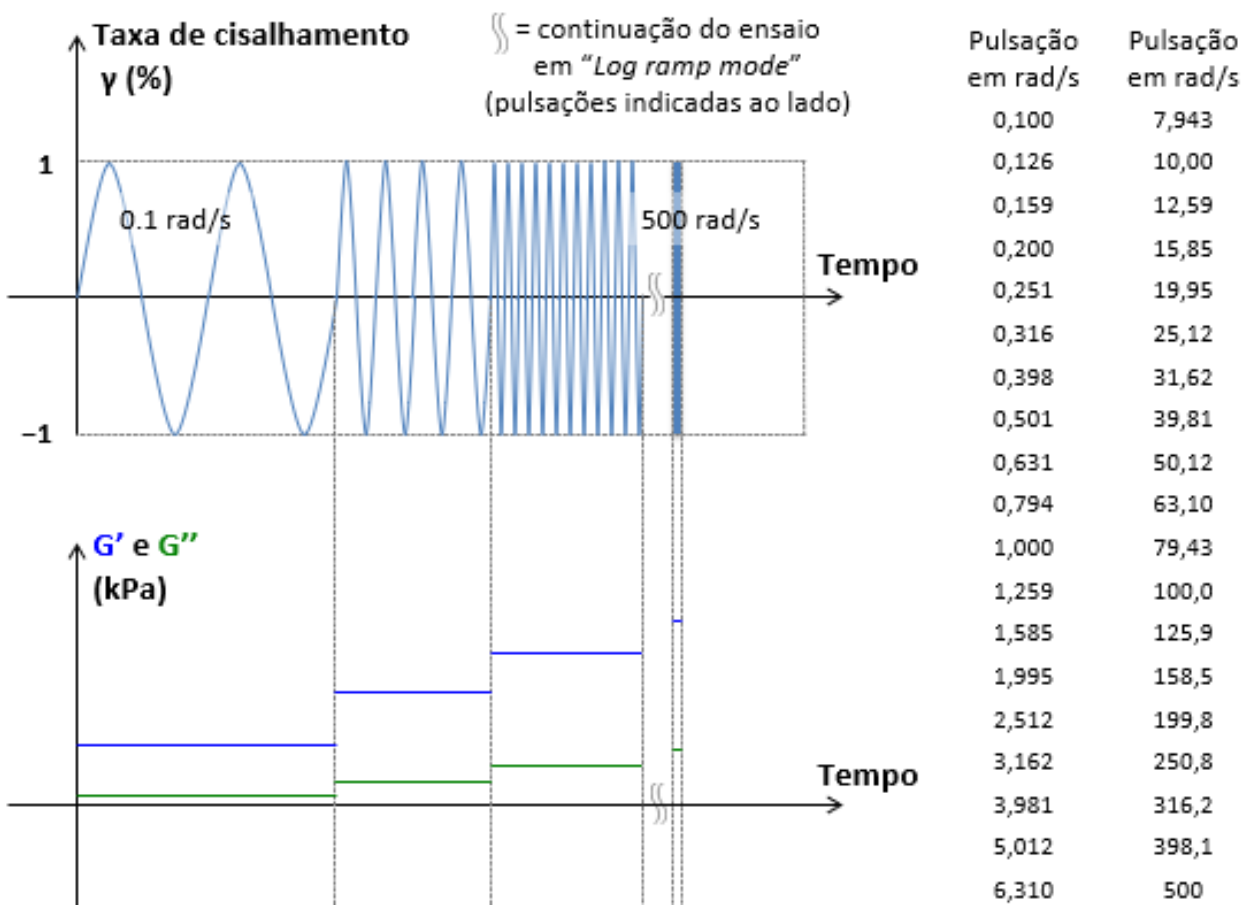

\section{Resultados e discussões}

\section{Ensaio de fluxo}

É possível comparar tintas aplicando critérios que as categorizam de acordo com seus processos de uso (DEKA; DEY, 2013). Os ensaios de fluxo realizados analisaram como a viscosidade aparente das amostras se comportam quando uma ampla taxa de cisalhamento é aplicada. Além disso, Deka e Dey (2013) afirmam que, com relação ao ensaio de fluxo, a alta viscosidade em baixas taxas de cisalhamento é uma característica que as tintas devem apresentar de forma geral, pois isso proporciona boas propriedades de resistência à sedimentação e estabilidade do pigmento em condições de armazenamento.

As Figuras 7, 8 e 9 mostram a comparação entre as tintas classificadas por tipo, econômicas, standard e premium, respectivamente. Na Figura 7, percebe-se que as tintas testadas da fabricante A, para as diluições de $0 \%$ e $10 \%$, apresentam maior estabilidade à sedimentação, uma vez que suas viscosidades aparentes são maiores em baixas taxas de cisalhamento, o que não ocorre para a diluição de $20 \%$, em que se observa uma viscosidade aparente inferior, nas mesmas taxas. Enquanto isso, as tintas testadas da fabricante B apresentaram viscosidades aparentes altas para baixas taxas de cisalhamento em todas as diluições, mostrando boa resistência à sedimentação (em condições de armazenamento) e maior resistência ao escorrimento. É possível perceber também que as diluições não interferiram na redução da viscosidade aparente dessa tinta, na classe econômica.

Em relação às amostras da classe standard, percebe-se na Figura 8 que ao se comparar as tintas A e B, é possível identificar que a $\mathrm{B}$ apresenta viscosidade aparente maior em praticamente todas as taxas de cisalhamento analisadas e em todas as diluições, possuindo maiores valores na diluição de $0 \%$ em baixas taxas de cisalhamento. Essa viscosidade aparente mais alta pode gerar uma dificuldade maior de nivelamento das camadas aplicadas das tintas da marca $\mathrm{B}$ em relação às da marca $\mathrm{A}$. As tintas $\mathrm{A}$ e $\mathrm{B}$ puras da classe standard podem apresentar maior estabilidade no período de estocagem, com maior resistência à segregação dos componentes, devido aos elevados valores de viscosidade aparente em baixas taxas de cisalhamento. Em comparação com a tinta B, a tinta A se mostrou melhor para aplicação, pois apresentou viscosidade aparente menor para taxas de cisalhamento mais elevadas, em todas as diluições. A tinta A para $10 \%$ de diluição apresentou valores muito similares à tinta B para uma diluição de $20 \%$, esta apresentou maior potencial de aplicação que as demais diluições do tipo B. 
A Figura 9 compara as amostras da classe premium. Percebe-se que, para as taxas de cisalhamento inferiores a $1 \mathrm{~s}^{-1}$, as amostras da marca A apresentam maiores valores de viscosidade aparente, o que leva a se esperar melhor comportamento em relação à resistência à segregação e ao escorrimento. Já nas taxas superiores a 1 $\mathrm{s}^{-1}$, as tintas da marca A passam a apresentar uma viscosidade aparente menor, o que pode facilitar a aplicação por meio de pincéis, rolos ou até mesmo spray. Por outro lado, as tintas do fabricante B apresentaram resultados de reometria que indicam maior probabilidade de sedimentação para taxas mais baixas. Sublinha-se a importância de fazer comparações quanto à viscosidade aparente associadas a uma dada taxa de cisalhamento, escolhida de maneira pertinente ao fenômeno envolvido. Por exemplo, para o rendimento, que é medido com rolo de acordo com a NBR 14942 (ABNT, 2019b), a ordem de grandeza a ser adotada para a taxa de cisalhamento é por volta de $3.000 \mathrm{~s}^{-1}$ (cf. Figura 2). Isso é discutido na seção "Ensaio de Tixotropia (3ITT)", em que há um foco mais específico na análise do comportamento reológico para essa ordem de grandeza de taxa de cisalhamento.

Analisando de forma geral todas as amostras caracterizadas quanto ao ensaio de fluxo, é possível perceber que as tintas apresentaram maior variabilidade nos valores de viscosidade aparente até a taxa de $1 \mathrm{~s}^{-1}$, ou seja, para taxas mais baixas é mais difícil prever o comportamento das amostras, com base nos dados analisados. As tintas puras standard das duas marcas são as que apresentam maiores valores de viscosidade aparente, particularmente em baixas taxas de cisalhamento, apresentando, assim, na prática, a maior probabilidade de resistência à segregação durante armazenamento e ao escorrimento após aplicação, com destaque para as técnicas que demandam alto cisalhamento, como o spray.

Figura 7 - Comparação entre tintas econômicas

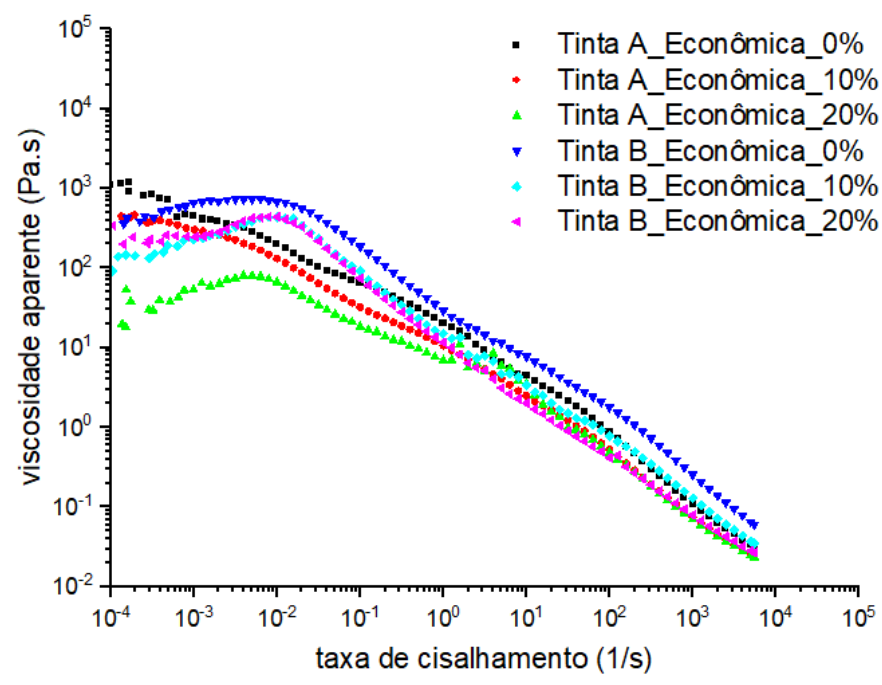

Figura 8 - Comparação entre tintas standard

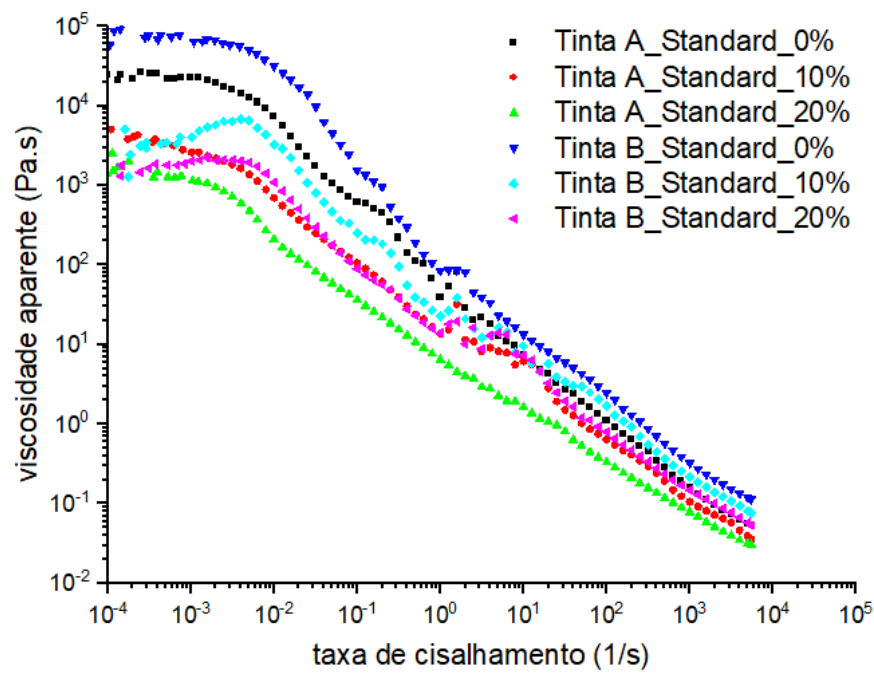

232 Machado, A. M. L.; Noberto, C. C.; Damasceno Filho, F. E.; Silva, W. M. M. da; Babadopulos, L. F. de A. L.; Medeiros Júnior, M. S. 
Figura 9 - Comparação entre tintas premium

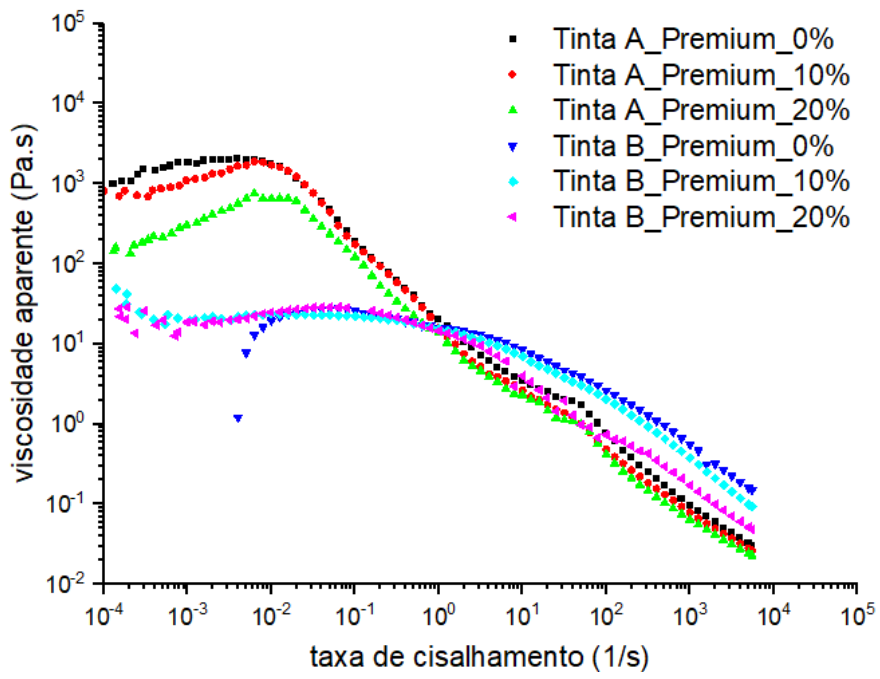

Observa-se ainda que ocorre um aumento de viscosidade aparente em baixas taxas de cisalhamento, que passa em seguida a diminuir com o aumento da taxa a partir de cerca de $10^{-2} \mathrm{~s}^{-1}$. Isso é particularmente evidente no caso da tinta B premium sem qualquer diluição. Parece haver, segundo os resultados, um efeito da diluição sobre esse comportamento. Porém, sendo a tinta B premium sem diluição a que apresentou esse fenômeno de maneira mais marcante, acredita-se que possa se tratar de um fenômeno de acomodação das tintas, possivelmente ligada a uma continuação do processo de homogeneização durante o ensaio. Isso se deu apesar do esforço de pré-homogeneização (Figura 3), nas tintas diluídas. Sublinha-se que esse processo foi feito manualmente nas tintas não diluídas, com auxílio de uma espátula metálica.

Para o fabricante $\mathrm{B}$, único que disponibilizou para divulgação os dados de teores de sólidos (Tabela 2), percebeu-se uma associação entre o teor de sólidos e a viscosidade aparente máxima das tintas (que ocorre a baixas taxas de cisalhamento) em cada uma das tintas, conforme apresentado na Figura 10. A figura foi construída considerando os diferentes níveis de diluição das tintas, com o teor de sólidos após diluição. Esse valor de viscosidade aparente máxima é observado em geral para taxas de cisalhamento relativamente baixas (aproximadamente de $10^{-2} \mathrm{~s}^{-1}$ a $1 \mathrm{~s}^{-1}$ ). Porém, conforme evidenciam as Figuras 7 e 9, nas quais se vê uma inversão na ordem das tintas mais viscosas a altas taxas de cisalhamento, essa não é uma regra geral a ser seguida, podendo o maior teor de sólidos estar associado a menores viscosidades aparentes, dependendo da taxa de cisalhamento analisada. Isso se deve possivelmente ao caráter viscoelástico da resina, que, em função da taxa de cisalhamento aplicada, pode apresentar rigidez que varia diferentemente das inclusões sólidas. Acrescenta-se que a relação entre o teor de sólidos e a viscosidade aparente depende ainda das propriedades das resinas utilizadas, o que inviabiliza a identificação de relações mais fundamentais entre a microestrutura das tintas e o comportamento reológico em macroescala apenas com os dados disponíveis nesta pesquisa.

\section{Ensaio de tixotropia (3ITT)}

O ensaio de tixotropia em três intervalos, do inglês Three Interval Thixotropy Test (3ITT), representa, de maneira mais aproximada, a situação real de aplicação das tintas com pincel ou rolo (BHAVSAR; SHREEPATHI, 2016).

As Figuras 11 e 12, abaixo, mostram os gráficos de resultados do ensaio 3ITT para as tintas das classes econômica e standard, respectivamente. Comparadas às tintas da marca $\mathrm{B}$, as da marca $\mathrm{A}$, para diferentes diluições, apresentaram viscosidade aparente inferior no início e no final do ensaio, cuja taxa de cisalhamento aplicada foi de $0,100 \mathrm{~s}^{-1}$. Por sua vez, as tintas da marca B apresentaram viscosidade aparente inicial alta. Percebeu-se que, para as duas marcas de tintas, o aumento da taxa de cisalhamento $\left(3.000 \mathrm{~s}^{-1}\right)$ resultou em uma viscosidade aparente apropriada para aplicação e, logo em seguida, com a redução da taxa de cisalhamento, houve uma recuperação da viscosidade aparente. Na Figura 11, referente à classe econômica, as tintas da marca $\mathrm{B}$ apresentaram recuperação mais rápida que as da marca $\mathrm{A}$. Em contrapartida, na Figura 12, houve uma inversão. As tintas que apresentaram recuperação mais lenta, tinta A 
econômica e tinta B standard, tendem a ser mais propensas a manifestar defeitos de nivelamento do filme e escorrimento após a aplicação.

A viscosidade aparente à baixa taxa de cisalhamento diminuiu com o aumento da porcentagem de diluição das tintas, conforme as Figuras 11, 12 e 13, para todas as classes. A viscosidade aparente a alta taxa de cisalhamento permaneceu próxima a zero, o que é uma característica desejável para as tintas, pois indica facilidade na aplicação por meio de pincéis, rolos e spray.

A tinta $\mathrm{B}$ do tipo premium não apresentou o mesmo grau de comportamento tixotrópico que a tinta $\mathrm{A}$ em nenhuma das diluições, como se pode notar na Figura 13, em que se observa um comportamento quase linear em todos os três intervalos, com uma queda instantânea na viscosidade quando a taxa é aumentada e uma recuperação também instantânea quando essa taxa é removida. A variação na viscosidade entre os intervalos também é mínima. Em contrapartida, as tintas A apresentaram comportamento tixotrópico mais acentuado, representado pela relevante variação na viscosidade aparente para uma alta taxa de cisalhamento e posterior recuperação, lenta e não linear, dependente do tempo, quando há redução na taxa. Dessa forma, a tinta B premium tende a ter maior probabilidade de escorrer que a tinta $\mathrm{A}$, uma vez que mantém praticamente a mesma viscosidade aparente antes, durante e após a aplicação, e em níveis mais baixos que a tinta A.

A Tabela 3 mostra a porcentagem de variação com o tempo para as tintas de ambos os fabricantes, sem diluições.

Figura 10 - Correlação entre o teor de sólidos e a viscosidade aparente de pico das tintas B

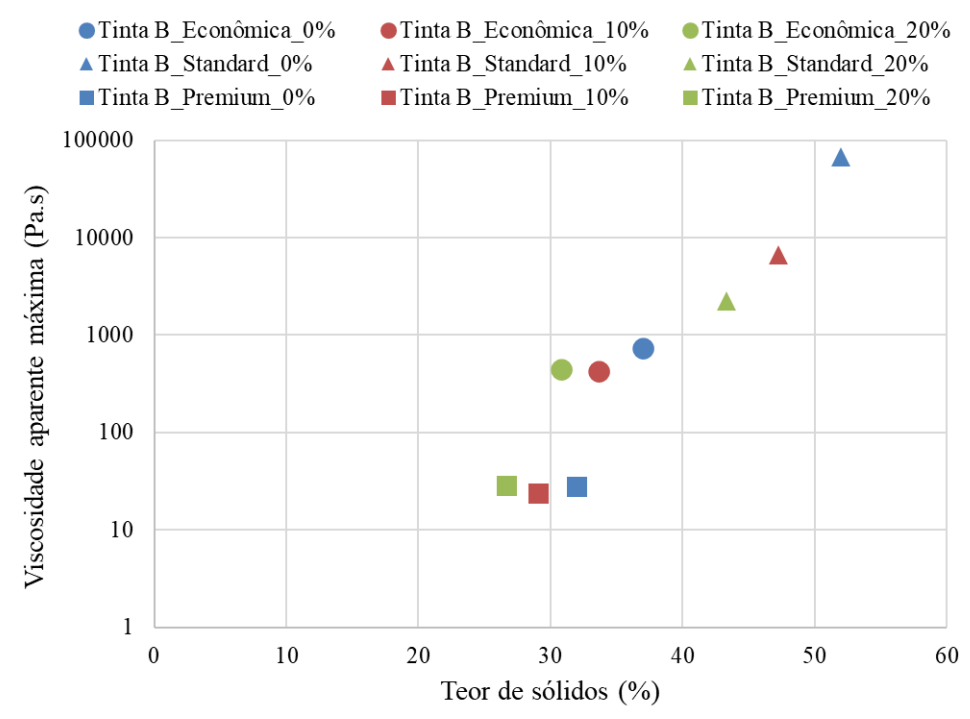

Figura 11 - Resultado do ensaio 3ITT para tintas da classe econômica

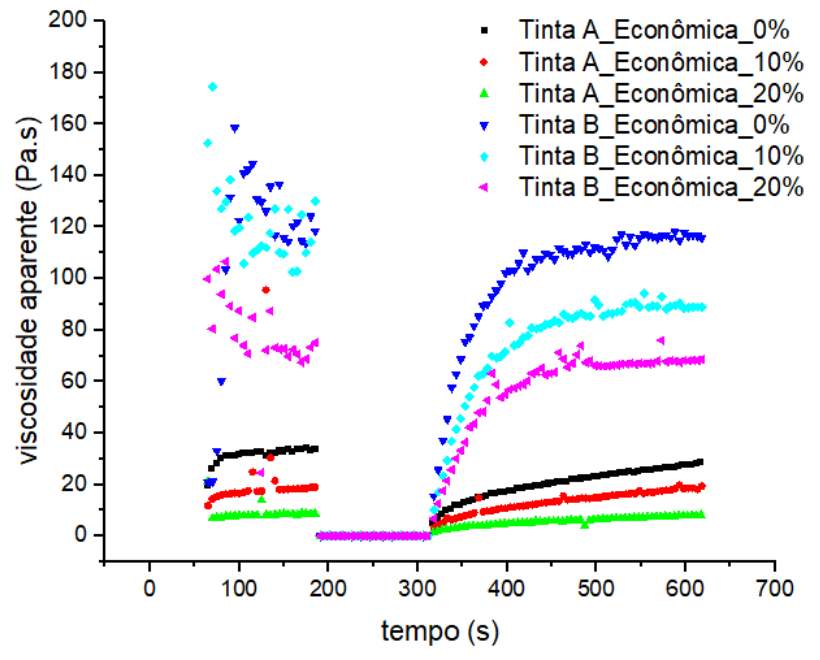

234 Machado, A. M. L.; Noberto, C. C.; Damasceno Filho, F. E.; Silva, W. M. M. da; Babadopulos, L. F. de A. L.; Medeiros Júnior, M. S. 
Figura 12 - Resultado do ensaio 3ITT para tintas da classe standard

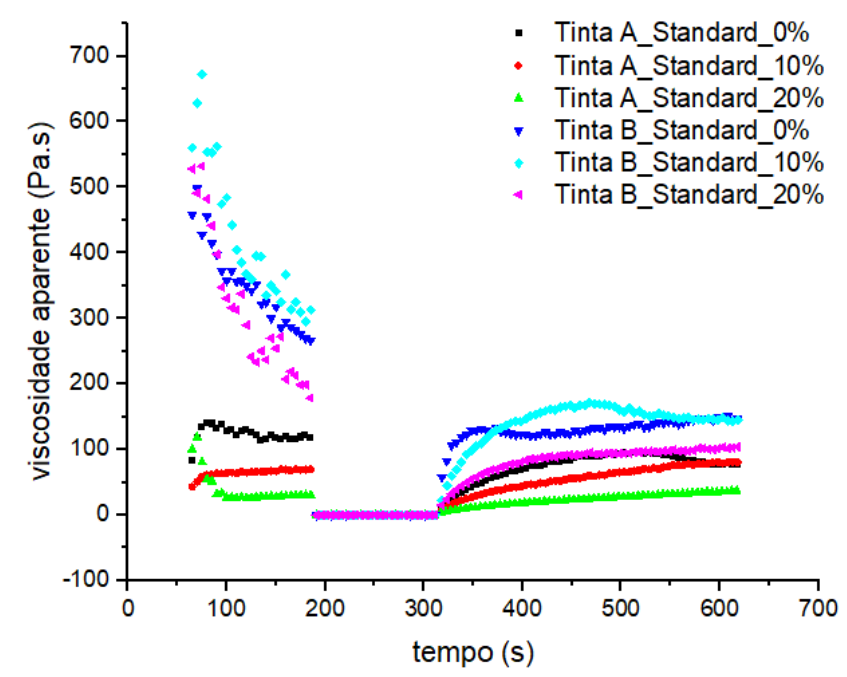

Figura 13 - Resultado do ensaio 3ITT para as tintas da classe premium

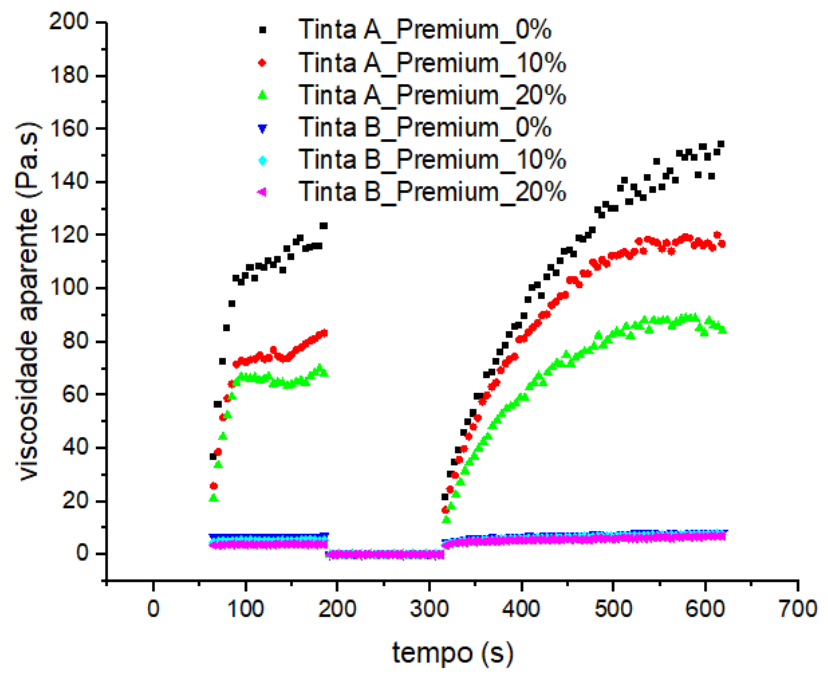

Tabela 3 - Porcentagem de recuperação ao longo do tempo para tintas não diluídas

\begin{tabular}{|c|c|c|c|c|c|c|c|c|c|c|c|}
\hline \multirow{2}{*}{ Fabricante } & \multirow{2}{*}{ Tipo } & \multirow{2}{*}{$\begin{array}{c}\text { Viscosidade } \\
\text { aparente a } \\
\text { 0,100s }^{-1} \text { (Pa.s) } \\
\end{array}$} & \multirow{2}{*}{$\begin{array}{c}\text { Viscosidade } \\
\text { aparente a } \\
\text { 3.000s }{ }^{-1}(\text { Pa.s) } \\
\end{array}$} & \multicolumn{8}{|c|}{ Porcentagem de recuperação após } \\
\hline & & & & $10 \mathrm{~s}$ & $30 \mathrm{~s}$ & $60 \mathrm{~s}$ & $100 s$ & $120 \mathrm{~s}$ & $180 \mathrm{~s}$ & $240 \mathrm{~s}$ & $300 \mathrm{~s}$ \\
\hline $\mathrm{A}$ & Econômica & 31,47 & 0,057 & 22,7 & 37,2 & 47,9 & 58,3 & 62,4 & 72,5 & 81,7 & 91,3 \\
\hline A & Standard & 122,49 & 0,059 & 15,1 & 31,6 & 47,4 & 60,6 & 65,4 & 74,8 & 72,7 & 63,4 \\
\hline A & Premium & 102,82 & 0,049 & 29,1 & 48,6 & 70,8 & 98,3 & 104,7 & 127,9 & 134,4 & 147,0 \\
\hline $\mathrm{B}$ & Econômica & 111,91 & 0,087 & 22,9 & 56,2 & 79,9 & 94,6 & 96,0 & 98,4 & 104,7 & 104,1 \\
\hline B & Standard & 349,37 & 0,129 & 23,6 & 35,1 & 37,8 & 34,7 & 35,2 & 38,5 & 40,5 & 41,8 \\
\hline B & Premium & 6,61 & 0,137 & 73,0 & 89,5 & 91,0 & 103,1 & 102,3 & 106,3 & 119,0 & 124,2 \\
\hline
\end{tabular}

As tintas econômica e premium do fabricante B têm o processo de recuperação mais rápido que as do mesmo tipo do fabricante A. Esse fenômeno é muito mais evidente para a tinta premium do fabricante B, que apresenta uma recuperação de $73 \%$ apenas 10 s após a retirada da alta taxa de cisalhamento, enquanto a mesma tinta do fabricante A apresenta, para o mesmo tempo, 29,1\% de recuperação. Contudo, a viscosidade da tinta B premium se mostrou baixa, mesmo após a recuperação, o que pode favorecer o escorrimento desta tinta, em detrimento da tinta A. Um tempo de recuperação muito curto pode prejudicar o processo de 
nivelamento das tintas, já que pouco tempo é permitido para que as partículas se orientem, cubram pequenas falhas e resultem em um filme uniforme (MOOLMAN, 2003).

Quanto mais rápido o material recuperar a viscosidade após aplicação de uma alta taxa de cisalhamento, menor será a probabilidade de ocorrer o escorrimento da tinta; entretanto, deve-se permitir o tempo necessário para que ocorra o nivelamento, para obtenção de um filme uniforme. De acordo com Bhavsar e Shreepathi (2016), 100s após a retirada da alta taxa de cisalhamento é um tempo razoável para que a tinta flua e nivele, intervalos superiores contam com alguns riscos indesejáveis, como evaporação da água, perda de solvente e escorrimento. A tinta com menor índice de recuperação após 100s é a do tipo standard do fabricante B, com apenas 37,8\%. Embora a recuperação lenta permita o nivelamento, a probabilidade de escorrimento nesse caso é maior.

Finalmente, de maneira a evidenciar a ligação entre o comportamento reológico medido nos ensaios e um indicador prático classicamente utilizado na indústria de tintas, apresenta-se a Figura 14. Essa figura relaciona a viscosidade aparente das tintas medidas em duas diferentes taxas de cisalhamento $\left(0,100 \mathrm{~s}^{-1} \mathrm{e}^{-}\right.$ $3.000 \mathrm{~s}^{-1}$ ) com o rendimento reportado pelos fabricantes, sendo ele medido com uso de rolos de acordo com a NBR 14942 (ABNT, 2019b). Evidencia-se que, com relação à viscosidade aparente medida a $0,100 \mathrm{~s}^{-1}$, não há qualquer relação esperada, pois essa taxa de cisalhamento é correspondente a fenômenos de baixa taxa de carregamento, como a sedimentação, o nivelamento, o escorrimento, etc. Porém, a $3.000 \mathrm{~s}^{-1}$, que é uma taxa de cisalhamento compatível com a aplicação das tintas com rolo (Figura 2), a associação é esperada. Ela ficou evidenciada, com $\mathrm{R}^{2}$ da ordem de $86 \%$, com os dados gerados nesta pesquisa. Efeitos como pequenas variações de taxa de cisalhamento quando da aplicação das tintas com rolo por diferentes operadores no ensaio empírico podem justificar as flutuações. Além disso, a correspondência exata entre a taxa de cisalhamento aplicada no ensaio reológico e a de fato aplicada no campo não é possível de se obter, sendo o resultado uma aproximação.

\section{Ensaio de varredura de frequência}

A Figura 15 abaixo apresenta os valores de G' e G” para as tintas não diluídas da marca B. Nota-se que as tintas do tipo econômica e standard possuem G' superior a G' ao longo de todas as frequências, ou seja, apresentam comportamento mais próximos a um sólido do que a um líquido a pequenas deformações. Isso indica um grau mais elevado de estabilidade, de modo que tintas sejam menos propensas a sedimentar e a separar suas fases durante o tempo de estoque (MOOLMAN, 2003). A tinta do tipo standard apresenta ainda curvas para G' e G" quase paralelas entre si, assim o G" não será superior a G', o que demonstra a maior estabilidade dessa tinta em relação às demais. A tinta do tipo premium, por sua vez, apresenta G' e G' sobrepostos a baixas frequências, com o G" ultrapassando o G' para frequências superiores a $150 \mathrm{rad} / \mathrm{s}$. Isso evidencia a baixa estabilidade dessa tinta, para a qual a probabilidade de sedimentação e separação de fases durante a fase de estocagem é a maior em relação às demais.

Figura 14 - Correlações entre medidas empíricas de rendimento com o comportamento reológico das tintas conforme viscosidades aparentes medidas no ensaio 3ITT

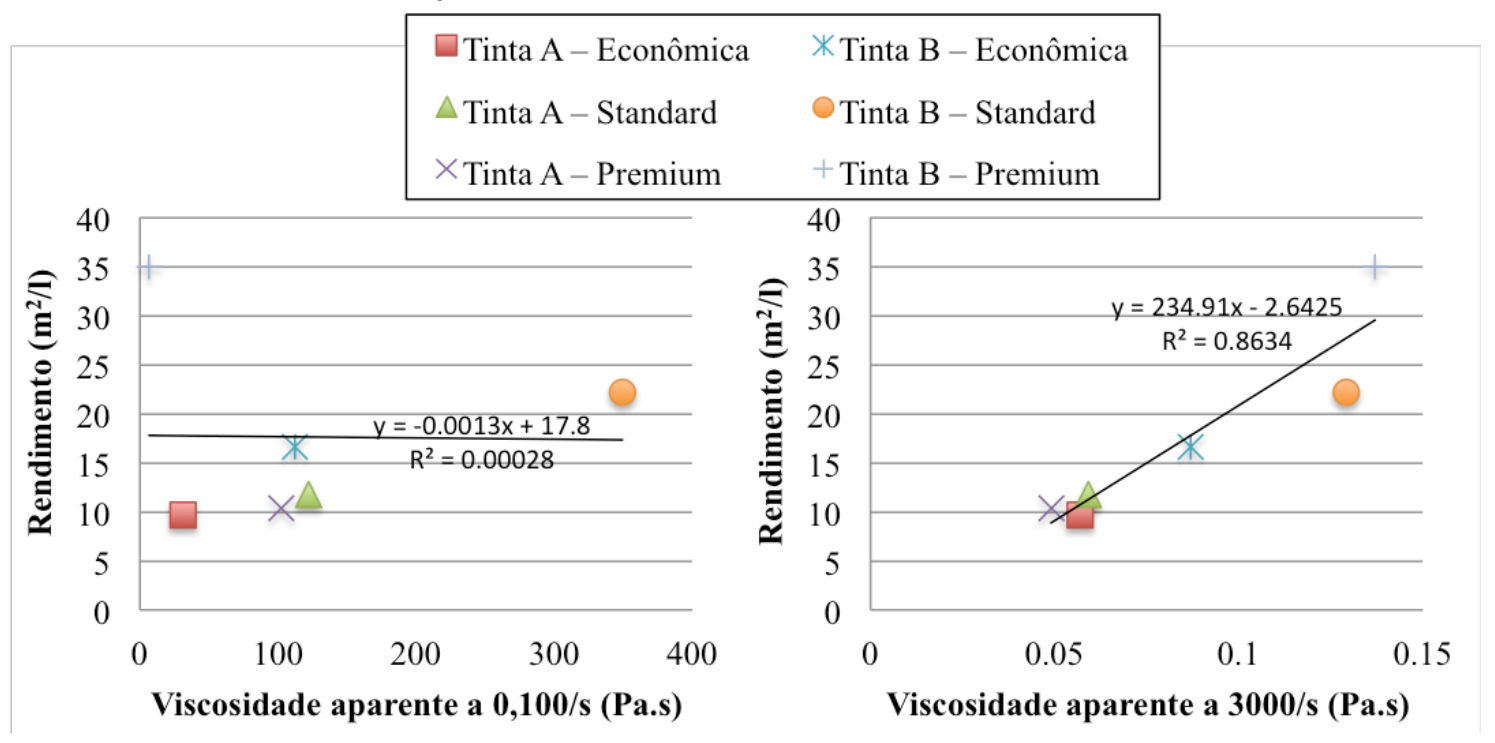

236 Machado, A. M. L.; Noberto, C. C.; Damasceno Filho, F. E.; Silva, W. M. M. da; Babadopulos, L. F. de A. L.; Medeiros Júnior, M. S. 
Figura 15 - Gráfico de varredura de frequência para tintas B não diluídas

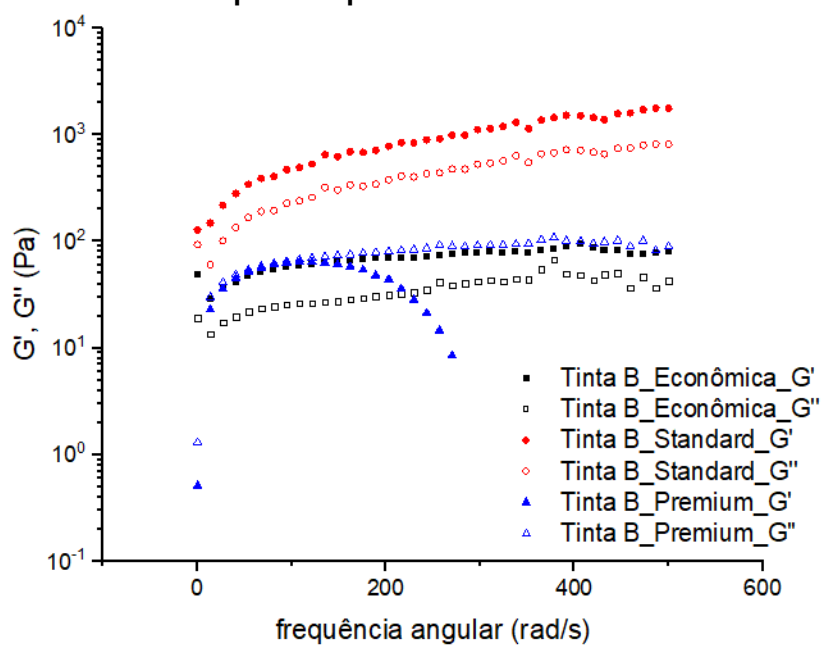

A Figura 16 mostra o mesmo ensaio, desta vez para as tintas da marca A não diluídas. Nota-se que os resultados foram semelhantes, à exceção da tinta do tipo econômica, que, para esse fabricante, apresenta maiores valores para os módulos G' e G'. Novamente, as tintas do tipo econômica e standard apresentam curvas onde G' é superior a G" ao longo de toda a curva, denotando a estabilidade das tintas durante o processo de estocagem. Embora a baixas frequências o módulo G' seja superior para a tinta tipo premium, também acontece uma inversão para altas frequências, ilustrando a menor estabilidade em relação às outras tintas. Entretanto, vale ressaltar que esta ainda é mais estável do que a mesma tinta do fabricante B, para a qual o G' não é superior ao G' nem a baixas frequências.

\section{Conclusão}

As propriedades reológicas de tintas acrílicas das classes econômica, standard e premium de dois fabricantes (A e B) foram estudadas por meio de ensaios de fluxo, tixotropia 3ITT e varredura de frequência. As conclusões deste trabalho podem ser sumarizadas como indicado abaixo:

(a) as curvas de fluxo mostraram que as tintas da classe standard apresentam maior probabilidade de resistência à segregação e ao escorrimento devido a sua elevada viscosidade aparente a baixas taxas de cisalhamento; houve pouca mudança no comportamento da tinta B premium nas diferentes diluições. De modo geral, as tintas da marca A são as que podem apresentar maior facilidade de aplicação para todas as classes;

(b) os resultados dos ensaios 3ITT mostraram que as tintas B econômica recuperam a viscosidade aparente mais rapidamente que as do fabricante A. Já para a classe standard, foram as tintas A que se recuperaram mais rapidamente. Para a classe premium, embora a marca B tenha apresentado uma rápida recuperação, a viscosidade aparente apresentou valores baixos e quase lineares (comportamento não tixotrópico), para todas as faixas de cisalhamento aplicadas, revelando uma probabilidade maior de manifestar problemas relacionados ao escorrimento;

(c) os resultados dos ensaios 3ITT foram utilizados para demonstrar a ligação fundamental entre o comportamento reológico das tintas e seu desempenho. Isso foi feito comparando os rendimentos reportados pelos fabricantes com os valores de viscosidade aparente medidos a $3.000 \mathrm{~s}^{-1}$ no ensaio 3ITT. Reitera-se que essa taxa de cisalhamento é compatível com a aplicação com rolo tal qual descrito na literatura. $\mathrm{O}$ rendimento está intimamente associado à viscosidade aparente a taxas de cisalhamento altas (da ordem de $3.000 \mathrm{~s}^{-1}$ ) das tintas;

(d) o ensaio de varredura de frequência mostrou que as tintas B econômica e standard possuem maior grau de estabilidade, sendo menos propensas a sedimentar e segregar durante o armazenamento; as tintas do tipo premium apresentaram os menores graus de estabilidade; e

(e) utilizando dados das três tintas do fabricante B e suas respectivas diluições a $10 \%$ e $20 \%$ (total de 9 pontos), foi identificada uma associação entre o teor de sólidos e a viscosidade aparente máxima, que ocorre a cerca de $10^{-2} \mathrm{~s}^{-1}$ das tintas. Observa-se possivelmente uma inversão nas tendências a altas taxas de cisalhamento, o que pode estar associado ao comportamento viscoelástico das resinas. 
Figura 16 - Gráfico de varredura de frequência para tintas A não diluídas

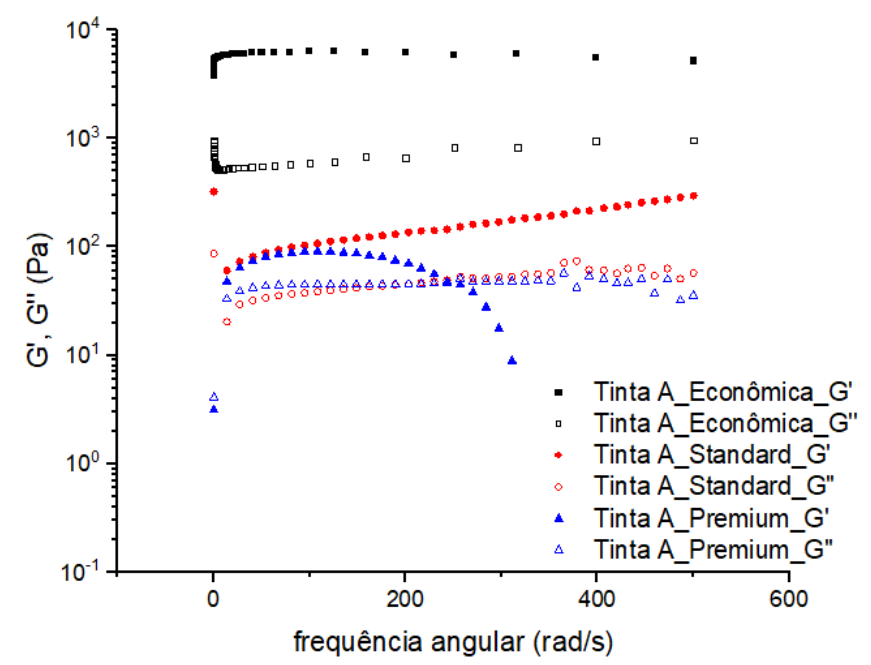

Vale destacar que este artigo possui caráter exploratório, que visava aplicar os conhecimentos da literatura de reologia, relacionando as propriedades fundamentais com o comportamento de campo. Com base no estudo realizado, foi possível comparar o comportamento reológico das tintas em diferentes carregamentos, buscando a compreensão de efeitos do tempo e da taxa de cisalhamento na viscosidade e no comportamento tixotrópico. Relacionou-se esses comportamentos com o nivelamento, a resistência ao escorrimento e à sedimentação durante o armazenamento, a facilidade e adequabilidade da aplicação, entre outros, por meio de indicações da literatura. $\mathrm{O}$ entendimento dos parâmetros se torna essencial para atender a um padrão de desempenho e de qualidade.

Para um dos comportamentos práticos, relativo ao rendimento, demonstrou-se a associação entre o comportamento prático e o comportamento medido de maneira objetiva por meio de ensaios reológicos (viscosidade aparente a $3.000 \mathrm{~s}^{-1}$ ). Relações com propriedades de tixotropia poderão ser exploradas de maneira mais aprofundada em trabalhos futuros.

\section{Referências}

ABRAFATI. Glossário. Disponível em: https://abrafati.com.br/glossario/. Acesso em: 19 dez. 2019.

ABRAFATI. O setor de tintas no Brasil. Available at: https://www.abrafati.com.br/en/o-setor-de-tintas-nobrasil/. Acesso em: 22 jun. 2021.

AMORIM, A. A. P. O. et al. Rheological, EMI and corrosion properties of epoxy coating with nanoparticle and conductive carbon black. SN Applied Sciences, v. 3, n. 2, p. 236, 28 fev. 2021.

ARMELIN, E. et al. A simple model to describe the thixotropic behavior of paints. Progress in Organic Coatings, v. 57, n. 3, p. 229-235, nov. 2006.

ASSOCIAÇÃO BRASILEIRA DE NORMAS TÉCNICAS. NBR 11702: tintas para construção civil: tintas, vernizes, texturas e complementos para edificações não industriais: classificação e requisitos. Rio de Janeiro, 2019a.

ASSOCIAÇÃO BRASILEIRA DE NORMAS TÉCNICAS. NBR 14942: tintas para construção civil: método para avaliação de desempenho de tintas para edificações não industriais: determinação do poder de cobertura de tinta seca. Rio de Janeiro, $2019 b$.

ASSOCIAÇÃO BRASILEIRA DE NORMAS TÉCNICAS. NBR 15079-1: tintas para construção civil: requisitos mínimos de desempenho: parte 1: tintas látex fosca nas cores claras. Rio de Janeiro, $2019 \mathrm{c}$.

ASSOCIAÇÃO BRASILEIRA DE NORMAS TÉCNICAS. NBR 15079-2: tintas para construção civil: requisitos mínimos de desempenho: parte 2: tintas látex semiacetinada, acetinada e semibrilho nas cores claras. Rio de Janeiro, 2019d. 
BHAVSAR, R.; SHREEPATHI, S. Evolving empirical rheological limits to predict flow-levelling and sag resistance of waterborne architectural paints. Progress in Organic Coatings, v. 101, p. 15-23, dez. 2016.

CARDOSO, F. de P. et al. Processos de produção e avaliação de requisitos de desempenho de tintas para a construção civil com pigmentos de solos. Ambiente Construído, Porto Alegre, v. 16, n. 4, p. 167-183, out./dez. 2016.

CHAKRABORTY, B. C.; RATNA, D. Viscoelasticity. In: CHAKRABORTY, B. C.; RATNA, D. Polymers for vibration damping applications. New York: Elsevier, 2020.

CHHABRA, R. P.; RICHARDSON, J. F. Non-newtonian fluid behaviour. In: CHHABRA, R. P.; RICHARDSON, J. F. Non-newtonian flow and applied rheology. New York: Elsevier, 2008.

DEKA, A.; DEY, N. Rheological studies of two component high build epoxy and polyurethane based high performance coatings. Journal of Coatings Technology and Research, v. 10, n. 3, p. 305-315, maio 2013.

ELEY, R. R. Applied rheology and architectural coating performance. Journal of Coatings Technology and Research, v. 16, n. 2, p. 263-305, 2019.

FARDI, T. et al. A novel methodological approach for the assessment of surface cleaning of acrylic emulsion paints. Microchemical Journal, v. 141, p. 25-39, set. 2018.

KARAKAŞ, F.; ÇELIK, M. S. Stabilization mechanism of main paint pigments. Progress in Organic Coatings, v. 123, p. 292-298, out. 2018.

LEE, W. Q. Thermal characterization of solvent-free epoxy coatings by rheology and kinetics combined. Journal of Coatings Technology and Research, v. 17, n. 1, p. 145-155, 5 jan. 2020.

MCKEEN, L. W. The components of paint. In: MCKEEN, L. W. Fluorinated Coatings and Finishes Handbook. New York: Elsevier, 2016.

MELLO, V. M.; SUAREZ, P. A. Z. The expressive ink formulations through history. Revista Virtual de Química, v. 4, n. 1, 2012.

MEWIS, J.; WAGNER, N. J. Thixotropy. Advances in Colloid and Interface Science, v. 147/148, p. 214 227, mar. 2009.

MEZGER, T. G. The rheology handbook. Hannover: Vincentz Network, 2012.

MOOLMAN, P. L. Rheological model for paint properties. Stellenbosch, 2008. 384 f. Tese (Doutorado em Engenharia Química) - Universidade de Stellenbosch, Stellenbosch, 2008.

MOOLMAN, P. L. Rheology of coating systems. Stellenbosch, 2003. 313 f. Dissertação (Mestrado em Engenharia Química) - Universidade de Stellenbosch, Stellenbosch, 2003.

NASCIMENTO, Z. C.; PINTO, P. R.; SIRQUEIRA, A. D. S. Rheological Studies of Conducting Acrylic Paint. Acta Scientiae et Technicae, v. 2, n. 2, jan. 2015.

SEELER, F. et al. Simulations and experimental investigation of paint film leveling. Journal of Coatings Technology and Research, v. 14, n. 4, p. 767-781, 5 jul. 2017.

SIRQUEIRA, A. da S. et al. Rheological behavior of acrylic paint blends based on polyaniline. Polímeros, v. 26, n. 3, p. 215-220, 18 ago. 2016.

VERKHOLANTSEV, V. V. Coatings additives, part VI: rheology of paints and applications. European Coatings Journal, v. 49, n. 6, p. 48-55, 1999.

ZHANG, H. et al. Rheological properties of waterborne polyurethane paints. Chinese Journal of Polymer Science, v. 33, n. 12, p. 1750-1756, 21 dez. 2015.

\section{Agradecimentos}

Os autores agradecem à Coordenação de Aperfeiçoamento de Pessoal de Nível Superior (Capes), ao Conselho Nacional de Desenvolvimento Científico e Tecnológico (CNPq), ao Programa de Pós-Graduação em Engenharia Civil: Estruturas e Construção Civil (PEC/UFC), ao Instituto Nacional de Ciência e Tecnologia de Caracterização de Materiais para Infraestrutura (INCT-Infra) e aos fabricantes de tintas que doaram as amostras para a realização da pesquisa. 


\title{
Amanda Moreira Lima Machado
}

Programa de Pós-Graduação em Engenharia Civil: Estruturas e Construção Civil | Universidade Federal do Ceará | Bloco 733, Campus do Pici, s/n | Fortaleza - CE - Brasil | CEP 60440-900 | Tel.: (85) 3366-9607 | E-mail: amandamlmachado@alu.ufc.br

\section{Camila Carvalho Noberto}

Programa de Pós-Graduação em Engenharia Civil: Estruturas e Construção Civil | Universidade Federal do Ceará | E-mail: camilacn@alu.ufc.br

\section{Francisco Estevão Damasceno Filho}

Programa de Pós-Graduação em Engenharia Civil: Estruturas e Construção Civil | Universidade Federal do Ceará | E-mail: damascenoestevao@alu.ufc.br

\section{Wyoskynaria Mihaly Maia da Silva}

Programa de Pós-Graduação em Engenharia Civil: Estruturas e Construção Civil | Universidade Federal do Ceará | E-mail: wyoskynaria@alu.ufc.br

\section{Lucas Feitosa de Albuquerque Lima Babadopulos}

Programa de Pós-Graduação em Engenharia Civil: Estruturas e Construção Civil, Departamento de Engenharia Estrutural e Construção Civil | Universidade Federal do Ceará | E-mail: babadopulos@ufc.br

\section{Marcelo Silva Medeiros Júnior}

Programa de Pós-Graduação em Engenharia Civil: Estruturas e Construção Civil, Departamento de Engenharia Estrutural e Construção Civil | Universidade Federal do Ceará | E-mail: marcelomedeiros@ufc.br

\author{
Ambiente Construído \\ Revista da Associação Nacional de Tecnologia do Ambiente Construído \\ Av. Osvaldo Aranha, $99-3^{\circ}$ andar, Centro \\ Porto Alegre - RS - Brasil \\ CEP 90035-190 \\ Telefone: +55 (51) 3308-4084 \\ www.seer.ufrgs.br/ambienteconstruido \\ www.scielo.br/ac \\ E-mail: ambienteconstruido@ufrgs.br
}

240 Machado, A. M. L.; Noberto, C. C.; Damasceno Filho, F. E.; Silva, W. M. M. da; Babadopulos, L. F. de A. L.; Medeiros Júnior, M. S. 